\title{
Pattern discrimination learning set formation in rats with brain stimulation as a reinforcer
}

ROGER N. JOHNSON 1

AMHERST COLLEGE

Three rats were criterion trained on 135-165 problems using 11 2-dimensional minimal stimuli. Reinforcement consisted of electrical stimulation of the lateral hypothalamus. All Ss demonstrated interproblem improvement.

The difficulties involved in establishing a true phylogenetic difference in learning ability among nonhuman mammals are discussed in two recent reviews (Warren, 1965a, b). It is concluded that very few problems reveal significant qualitative differences, thus making the task of the comparative psychologist more difficult. One problem which does appear to be sensitive to interspecies differences is that which follows the learning set paradigm. Since the pioneering work of Harlow $(1949,1950)$, the formation of learning sets has been widely studied, particularly with primates. Unfortunately, less attention has been directed atlearning set formation among relatively low mammals.

Perhaps the main reason for this neglect is the great difficulty encountered in running rodents and carnivores on learning set tasks. So far, it has proved difficult even to test learning set capacity in the common laboratory rat because of the heroic experimental effort needed to complete large numbers of problems. The methodological difficulties have led some investigators (Weaver \& Michels, 1961; Wright, Kay, \& Sime, 1963) to conclude that new procedures are required before learning set development can be tested adequately in relatively low mammals.

A proposed solution to the problem is the use of intracranial reinforcement(ICR) to replace conventional food reward. Although there is a sizeable literature regarding the use of brain stimulation in simple learning situations, this new technique has not been used extensively to study complex discrimination learning.

There are a number of advantages offered by the ICR technique. (1) Because there is no consummatory activity, trials and problems can be massed by running up to 25 discrete trials per minute. Such massing has been shown to reduce error scores (Johnson, 1966). (2) Because there is no satiation, to the reinforcer, it is possible to run animals continuously for extended periods. For example, it has been reported (Johnson, 1965) that in a single $19 \mathrm{hr}$. session one rat completed about 12,000 trials and learned nearly 400 brightness reversals. (3) If 2-dimensional stimuli are used, the entire procedure can be automated, thus making the continual presence of the experimenter unnecessary while also permitting precise experimental control of timing and spacing of trials and stimuli.

\section{Method}

The Ss were three male Charles River CD albino rats. One rat (No. 3) was experimentally naive while the others had received previous training on successive brightness reversals. Animals were stereotaxically implanted with chronic bipolar electrodes aimed at the region of the lateral hypothalamus.

The experimental chamber contained a black Plexiglas front with two holes $1-7 / 8 \mathrm{in}$. in diameter. Animals were required to poke their noses through either hole and push a translucent panel upon which the stimuli were projected from behind. The 11 minimal stimuli (Fig. 1) were provided by two Industrial Electronic readouts, model 10W02-44-L. A cable was attached to the animals via a swivel device (Johnson, Trehub, \& Pietskowski, 1966) which permitted free movement and prevented tangled electrode leads.

At the beginning of each daily session Ss were placed in the apparatus and their cables attached. Both panels were diffusely illuminated and a press with a force of $20 \mathrm{gm}$ on either panel resulted in reinforcement (.8 sec. of biphasic rectangular pulses of $1.0 \mathrm{msec}$. duration at a frequency of 100 per sec. from a Grass S-4 stimulator). After 20 warm-up trials the animals were responding actively and two patterns were introduced, the "correct" pattern appearing on the left or right according to a Gellerman series. Seven-tenths of a second after the stimuli were presented on each trial, the microswitches behind the panels were activated, permitting a response. A correct response led to $.8 \mathrm{sec}$. of reinforcing stimulation, and an incorrect response resulted in .2 sec. of buzzer operation. Following a response, both panels were deactivated

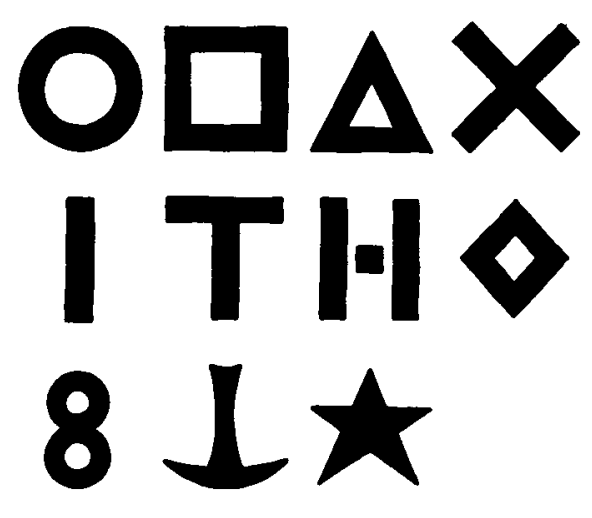

Fig. 1. The 11 patterns used as minimal stimuli. 


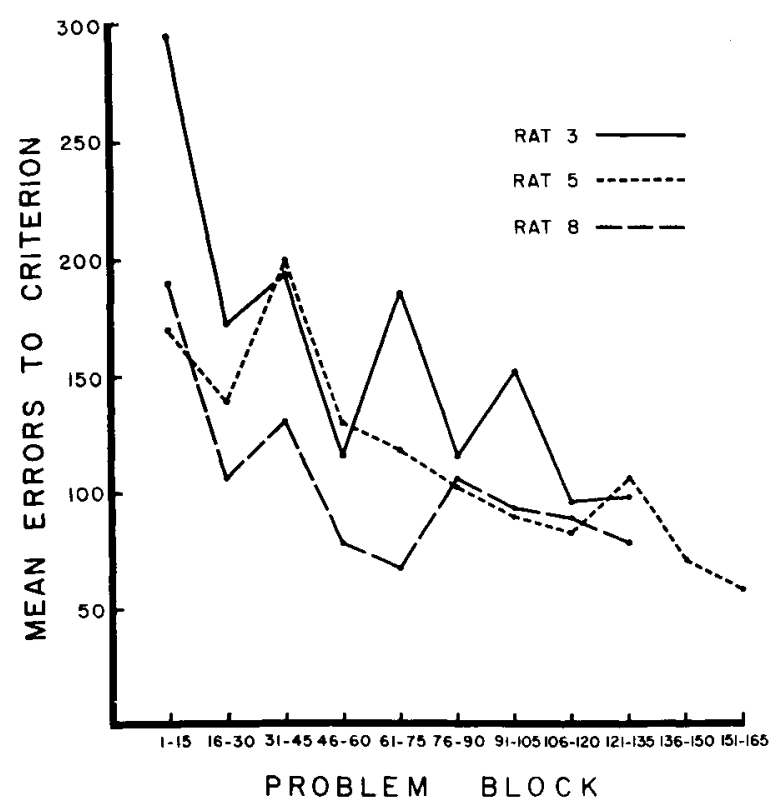

Fig. 2. Mean errors to criterion for each rat over blocks of 15 problems.

for an intertrial interval of $2.5 \mathrm{sec}$. The offset of the stimuli was delayed $.65 \mathrm{sec}$. after any response so that on every trial the stimuli were on for a minimum of $1.35 \mathrm{sec}$. The apparatus was completely dark during the intertrial interval.

The criterion employed was 10 correct responses in a row. When this criterion was met an overhead house light came on for an interproblem interval of $1 \mathrm{~min}$. All Ss were run approximately $2 \mathrm{hr}$. per day. Early in training, only a few problems were learned each day; later, animals mastered about 10 per day.

\section{Results and Discussion}

The mean errors to criterion for blocks of 15 problems can be seen in Fig. 2. Although there is a great deal of variability, all Ss clearly demonstrate interproblem improvement. The experiment was terminated after Ss pulled out their electrodes. At the end of the experiment, error scores appeared to be decreasing steadily, indicating that asymptotic performance had not yet been reached.

Although learning set formation has been demonstrated in rats when 3-dimensional stimuli were employed (Tyrell, 1963; Kay \& Oldfield-Box, 1963, 1965; Rollin, 1965, unpublished), previous attempts to obtain interproblem improvement using 2-dimensional stimuli (Koronakos \& Arnold, 1957; Weaver \& Michels, 1961; Oldfield-Box \& Kay, 1963; Wright, Kay, \& Sime, 1963) have been generally unsuccessful. The present experiment has been able to demonstrate pattern discrimination learning set formation mainly because of the use of an efficient technique which permits the administration of a large number of trials in a short period of time under automated conditions. Although it is not reasonable to compare these findings with conventional learning set data, it should be possible to use the ICR technique as a powerful tool for teasing out differences in learning ability among any animals which respond to ICR.

\section{References}

Harlow, H. F. The formation of learning sets. Psychol. Rev., 1949 , $56,51-65$.

Harlow, H. F. Analysis of discrimination learning by monkeys. J. exp. Psychol., 1950, 40, 26-39.

Johnson, $\mathbf{R}$. N. Use of reinforcing brain stimulation in discrimination learning. Percept. mot. Skills, 1965, 21, 366.

Johnson, R. N. Successive habit reversal learning in albino rats with brain stimulation as a reinforcer. Unpublished doctoral dissertation, University of Connecticut, 1966.

Johnson, R. N., Trehub, A., \& Pietskowski, E. An easily-constructed cable swivel device for brain stimulation experiments. J. exp. Anal. Behav., 1966, 9, 17-18.

Kay, H., \& Oldfield-Box, H. Use of 3-dimensional shapes for investigation of learning sets in the rat. Nature, 1963, 199, 1018.

Kay, H., O Oldfield-Box, H. A study of learning-sets in rats with an apparatus using 3-dimensional shapes. Anim. Behav., 1965 , $13,19-24$.

Koronakos, C., \& Amold, w. J. The formation of learning sets in rats. J. comp. physiol. Psychol., 1957, 50, 11-14.

Oldfield-Box, H., \& Kay, H. Four choice visual discrimination tasks in the formation of learning sets by rats. Anim. Behav., $1963,11,518-521$.

Tyrell, D. J. The formation of object discrimination learning sets by rats. Paper read at Eastern Psychologicol Association, New York, 1963.

Warren, J. M. The comparative psychology of learning. In Annual review of psychology. Palo Alto: Annual Reviews, Inc., 1965(a).

Warren, J. M. Primate learning in comparative perspective. In A. M. Schrier, H. F. Harlow, and F. Stollnitz, (Eds.), Behavior of nonhuman primates. Vol. 1, New York: Academic Press, 1965(b).

Weaver, L. A., \& Michels, K. M. Methodological factors affecting the formation of learning sets by rats. Anim. Behav., 1961, 9, 4-7.

Wright, P. L., Kay, H., \& Sime, M. E. The establishment of learning sets in rats. J. comp. physiol. Psychol., 1963, 56, 200-203.

\section{Note}

1. This research was carried out at the V. A. Hospital, Northampton, Mass. I am indebted to Dr. Arnold Trehub for his generous support, and to Mr. Edward Pietskowski for expert technical assistance. Thanks are aIso due to Dr. A. R. Rollin of the University of Connecticut. 